\title{
Effect of Rotation Speed on the Tribological and Conductive Behaviors of Rolling Current-Carrying Cu Pairs
}

\author{
Jiawei $\mathrm{Li}^{1}$, Chenfei Song ${ }^{1, *}$, Yanyan Zhang ${ }^{1}$, Yixiang Sun ${ }^{2}$, Tianhua Chen ${ }^{1}$, Li Wang ${ }^{3}$, Zili Liu ${ }^{3}$, \\ Shuai Wang ${ }^{1}$ and Yongzhen Zhang ${ }^{1}$ \\ ${ }^{1}$ National United Engineering Laboratory for Advanced Bearing Tribology, Henan University of Science and Technology, Luoyang, China \\ ${ }^{2}$ Wuhan Research Institute of Materials Protection, China Academy of Machinery Science and Technology, Wuhan, China \\ ${ }^{3}$ Qian Xuesen Laboratory of Space Technology, China Academy of Space Technology, Beijing, China
}

\begin{abstract}
The tribological and conductive performance of the rolling current-carrying pairs were studied at different rotation speeds based on the disc-disc $\mathrm{Cu}$ pairs. Whether the current was applied or not, the friction coefficient decreased with the increasing of rotation speed. The average contact resistance increased with the rotation speed and the applied current. The sharp fluctuation of the real-time current was proposed as the failure criterion for the rolling current-carrying pairs, and both the rotation speed and the current accelerated the failure process. Erosion pits and melting could be observed by SEM, and the surface oxidation could be detected by EDS on the failure surface. It was speculated that arc discharge appeared under high speed and large current conditions, which encouraged the transformation of damage mechanism from mechanical wear to arc erosion. These results may provide some useful suggestions on the failure mechanism and life tests of the electro-conductive rotary joints. [doi:10.2320/matertrans.MT-M2020267]
\end{abstract}

(Received August 20, 2020; Accepted December 1, 2020; Published February 25, 2021)

Keywords: rotation speed, current-carrying, arc erosion, oxidation

\section{Introduction}

Current-carrying contact pairs are the only pathways for power transport and signal transmission between moving surfaces, which are typical single-point failure components. ${ }^{1-3)}$ The traditional sliding current-carrying pairs have been widely used in the High-end equipment including current collection and return systems in rail transit, solar array in space ship, current collector in radar. ${ }^{4-6)}$ However, the sliding friction pairs show some disadvantages such as the high friction coefficient, high wear rate, high resistance fluctuation and serious arc erosion, which block their further application in the future. ${ }^{7}$ ) To overcome the disadvantages of sliding pairs, rolling contact pairs have been paid special attention, which comprises an outer raceway, rollers and an inner raceway. ${ }^{8)}$ In order to ensure the reasonable design and high reliability operation of the rolling current-carrying pairs, we must carry out the basic research on its performance and failure mechanism firstly.

As well known that the speed has a significant impact on the purely mechanical tribology. $\mathrm{Xu}$ et al. ${ }^{9)}$ indicated that the covering percentage of transfer layers on worn surfaces varied with the changing of sliding speeds and applied loads hence resulting in the distinct friction and wear characteristics. Hirasata et al. ${ }^{10)}$ reported that the dry friction coefficient on cast irons decreased with sliding speed because of the fluidity layer induced by temperature rise. Jayashree et al. ${ }^{11)}$ reported that friction coefficient decreased as the sliding speed was increased, since less time was provided for the formation of tough junctions. Meanwhile, the speed also has an important influence in the sliding current-carrying tribology. Zhang et al. ${ }^{12)}$ clarified that high sliding speeds could worsen the tribological and electrical conductivity properties. Xie et al. ${ }^{13)}$ studied the sliding electrical contact behaviors of $\mathrm{AuAgCu}$ brush/Au plating pairs at various

*Corresponding author, E-mail: cfsong@haust.edu.cn sliding speeds. The authors suggested that high sliding speed could cause the vibration and the change of real contact area, resulting in high contact voltage drop and obvious electric noise. In brief, the speed can change the contact state of current-carrying counter surfaces, and then further affect the tribological/conductive behaviors and material damage. Therefore, it is necessary to carry out basic research on the effect of velocity on rolling electrical contact from the perspective of current carrying tribology. Recently, the authors studied the tribological and conductive behaviors of the rolling pairs at $6 \mathrm{r} / \mathrm{min}$ and $4 \mathrm{r} / \mathrm{min}$, only slight adhesion and oxidation were observed on the rolling surface at such low speeds. It is still not clear that what will happen after acceleration. To this end, the speed dependence of the rolling current-carrying tribology is researched in this paper.

In this paper, a rolling current-carrying contact was realized by disc-disc $\mathrm{Cu}$ pairs. Tribological and conductive behaviors were tested at different speeds and various currents. A failure criterion of conductive function was proposed to determine the life of current-carrying contact. It was found that the lifetime was affected by the coupling effects of speed and current. The transformation of the material damage form was observed after the surface failure. These results may provide fundamental supports to the failure analysis and accelerated life test of the electro-conductive rotary joints.

\section{Experiments and Materials}

\subsection{Test equipment}

A self-developed the rolling current-carrying tribometer (FTM-CF100, Nanjing Bio-Inspired Technology Co., LTD, China) was used for the electric/tribological tests of the rolling friction pairs. As shown in Fig. 1, the mechanical parts of the tribometer mainly consist of load motor, load sensor, rotating motors, axis and torque sensor. The samples were fixed on the top of axis. The loading motor could push the axis B that installed on the ball screw move to the axis A. 


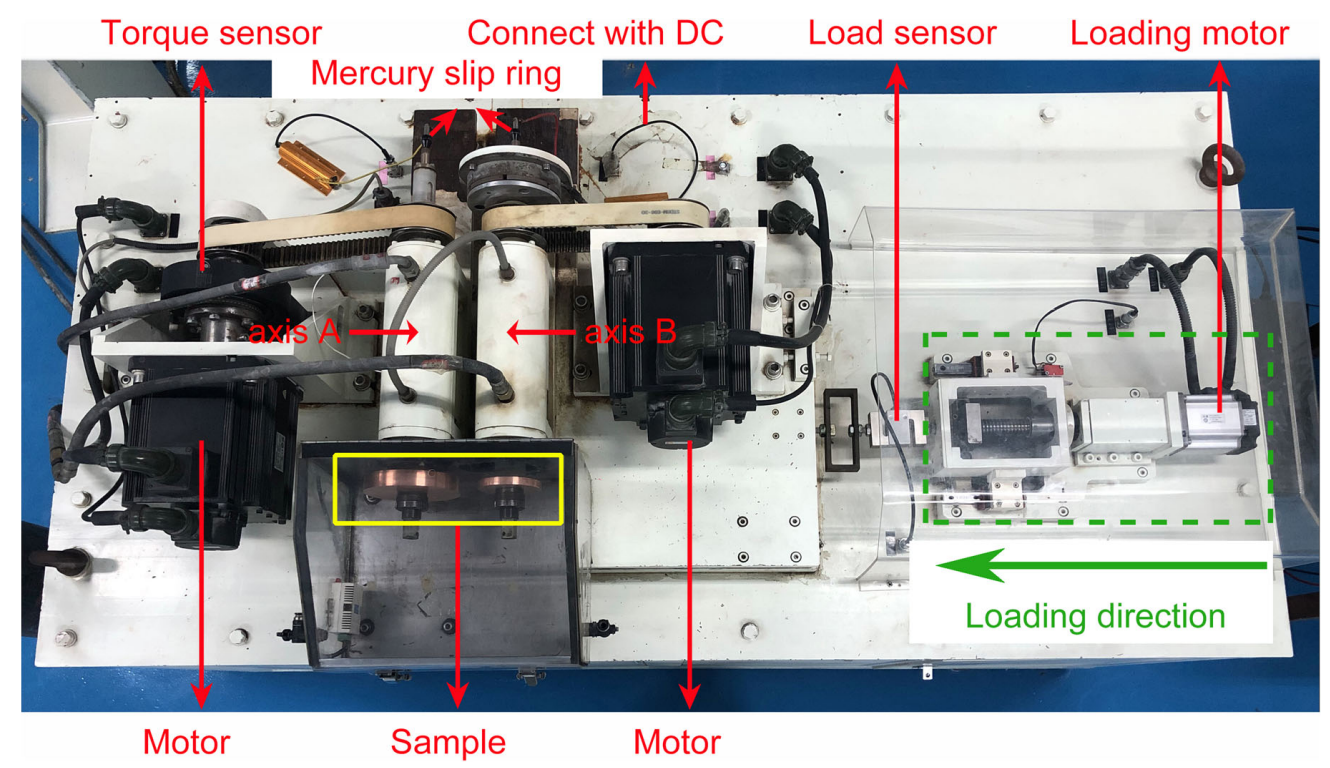

Fig. 1 The picture of rolling current-carrying tribometer.

(a)

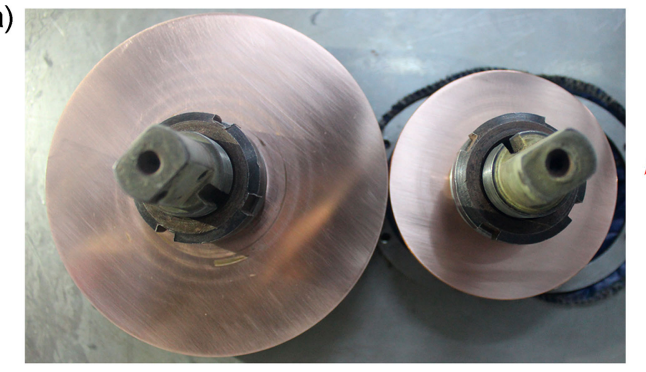

(b)

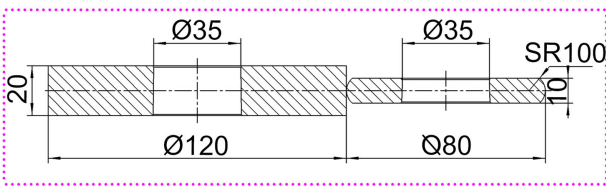

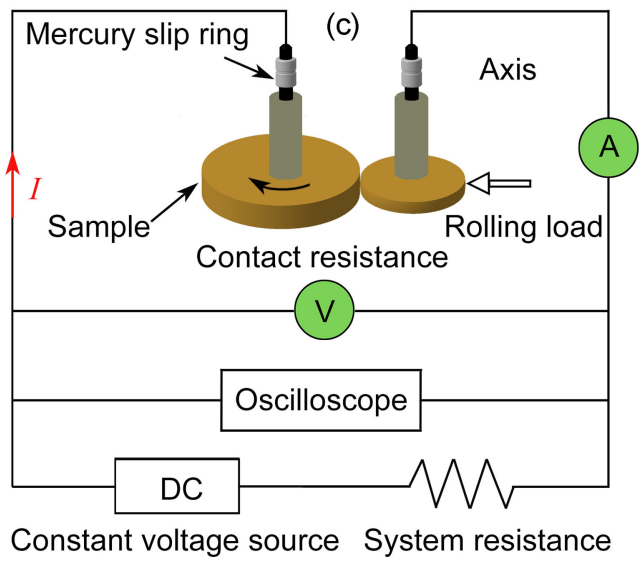

Fig. 2 Sketch map of the rolling pairs. (a) Disc-disc contact; (b) Schematic diagram of the appearance; (c) Schematic diagram of the rolling contact and electrical circuit system.

When the samples contacted closely, the load sensor would measure the contact load until it reached the preset value. There was a close-loop control system to assure that a constant load was applied throughout the test. The torque sensor was mounted on the rotating motor to measure friction force. Before each experiment, the torque zero point of the sample was calibrated to eliminate the influence of the support bearing friction. The conductive parts of the tribometer include regulated DC power, mercury slip ring, the core of the axis and the roller samples. The current could flow through the contact area when the samples contacted together, forming the current-carrying tribological contact.

\subsection{Materials}

The conductive node in the rolling conductive rotary joint was the elastic point contact area between copper-based roll rings and the raceways. Since the pure copper was the base compound for conductive roller materials such as brass and bronze, T2 pure copper (GB/T 2059-2008) was used to make rolling pairs for the tests (Fig. 2(a)). As shown in Fig. 2(b), one rolling sample was a cylinder of diameter $120 \mathrm{~mm}$, and the other was a disk with a diameter of $80 \mathrm{~mm}$ and a sidewall curvature radius of $100 \mathrm{~mm}$ (SR). The circuit diagram of the current-carrying system was shown in Fig. 2(c). A direct current was supplied by a constant voltage power (DC) flowing through the mercury slip ring, axis and samples. In order to maintain a uniform contact state, the surfaces of the test samples were sanded with the abrasive sandpaper of $600 \#, 1000 \#$ and $1500 \#$ grit in turn before each test. ${ }^{14)}$ Then the samples were cleaned by ultrasonic wave for 30 minutes in anhydrous alcohol.

\subsection{Experimental approach}

In the engineering application, the rolling current-carrying friction pairs worked at different rotation speeds. The typical low-speed ones are radar, aerospace return ring, collector ring, etc. ${ }^{15)}$ while the high-speed ones are ordinary train, rolling bearing, etc. ${ }^{16)}$ The rotational speeds of copper disk A-B were set to be $4 \mathrm{r} / \mathrm{min}-6 \mathrm{r} / \mathrm{min}, 240 \mathrm{r} / \mathrm{min}-360 \mathrm{r} / \mathrm{min}$, $300 \mathrm{r} / \mathrm{min}-450 \mathrm{r} / \mathrm{min}, 400 \mathrm{r} / \mathrm{min}-600 \mathrm{r} / \mathrm{min}, 600 \mathrm{r} / \mathrm{min}-900$ $\mathrm{r} / \mathrm{min}$ to simulate actual situation. There was no roll slip ratio when the rolling experiment, and the corresponding 
linear velocities were $0.025 \mathrm{~m} / \mathrm{s}, 1.508 \mathrm{~m} / \mathrm{s}, 1.885 \mathrm{~m} / \mathrm{s}$, $2.513 \mathrm{~m} / \mathrm{s}, 3.780 \mathrm{~m} / \mathrm{s}$, respectively.

According to the contact mechanics, ${ }^{17,18)}$ the critical Hertzian contact pressure for the yield of copper $P_{\mathrm{y}}$ was estimated as $393 \mathrm{MPa}$ since the yield strength $\sigma_{\mathrm{y}}$ was $244 \mathrm{MPa}$ and the Poisson ratio was 0.3. Considering geometry of the rollers in Fig. 2, the critical load for the yield of the copper could be established as about $180 \mathrm{~N}$. The experimental load was set as $180 \mathrm{~N}$ to obtain the elastic contact as well as the quick damage. The initial current was set as $0,1.0$, and $1.5 \mathrm{~A}$, which was the same as our previous work. ${ }^{19)}$ The tests under each working condition were repeated 5 times. Before and after each rolling experiment, the average temperature of the rolling surface was measured by an Infrared Thermometer (SMART SENSOR, AS-852B+).

During the rolling process, the friction coefficient $(\mu)$, the current $(I)$, and contact resistance $(R)$ can be obtained synchronously. The frequency of data acquisition was $1000 \mathrm{~Hz}$, each data acquisition lasted $10 \mathrm{~s}$ and the data acquisition interval was $50 \mathrm{~s}$. The dynamic characteristics of tribological and current-carrying properties could be described by the variability factor (coefficient of variation in statistics) $\delta_{\mathrm{x}} \cdot{ }^{20)}$

$$
\begin{gathered}
\sigma_{x}=\sqrt{\frac{1}{N} \sum_{i=1}^{n}\left(x_{i}-\bar{x}\right)^{2}} \\
\delta_{x}=\frac{\sigma_{x}}{\bar{x}} \times 100 \%
\end{gathered}
$$

Where $\sigma_{\mathrm{x}}$ is the standard deviation of data, $N$ is the number of data, $\bar{x}$ is the average value of data collected in a cycle of 10 seconds.

To analyse the wear loss, the sample mass was measured by an analytical balance with $1 \mathrm{mg}$ precision before and after the rolling.

\subsection{Surface analysis}

After the current-carrying rolling experiments, the wear area was cut into small cubes of $10 \mathrm{~mm} \times 10 \mathrm{~mm} \times 4 \mathrm{~mm}$ by wire-electrode cutting. Then, the samples were cleaned by ultrasonic wave for 30 minutes in anhydrous alcohol. In order to preliminarily check the damage degree of contact surface, the samples were observed by an optical microscopy (OM, DMi 8C, Leica, Germany) firstly. To discuss the mechanism of the surface damage, the morphologies were investigated by a scanning electron microscope (SEM, TESCAN, VEGA $3 \mathrm{SBH}$ ) and the components were analyzed by energy dispersive spectrometer (EDS, EDAX Octane SDD Series, USA). The atomic ratio of $\mathrm{O}: \mathrm{Cu}$ was calculated based on the EDS spectrum. The surface profile and roughness were observed by white light interference 3D profilometer (Nano Focus $\mu$ surf expert, Germany). Surface conductivity was measured by an atomic force microscopy (AFM, SPM 9700HT, Shimadzu, Japan) in conductive mode. The AFM probe (CDT-CONTR, Nanosensors, Switzerland) was coated with a conductive diamond film, whose spring constant was $0.78 \mathrm{~N} / \mathrm{m}$. During AFM scanning, the operating point was set to $0.5 \mathrm{~V}$ and the sample bias was set to $0.5 \mathrm{~V}$. The voltage range for the volt-ampere curves measurement was $-1.5 \sim+1.5 \mathrm{~V}$.

\section{Results and Discussion}

\subsection{Conductive properties of $\mathrm{Cu} / \mathrm{Cu}$ rolling at different rotation speeds}

During the rolling tests, the real-time current and friction coefficient could be monitored. Figure 3(a) displayed a series of current curves of the repeated experiments, the initial current was $1.0 \mathrm{~A}$. At the speed of $4 \mathrm{r} / \mathrm{min}$, the tests lasted for 4 hours and the total number of revolutions was 960 rounds, the current was very stable. At the speed of $240 \mathrm{r} / \mathrm{min}$, the rolling pairs worked 57600 revolutions (4 hours), the current still kept stable. At the higher speed of 300, 400 and 600 $\mathrm{r} / \mathrm{min}$, the current showed obvious pulse fluctuation after rolling for 13500 revolutions (45 minutes), 12000 revolutions (30 minutes) and 8400 revolutions (14 minutes), respectively. The higher the rotation speed, the earlier current fluctuation appeared. The current fluctuation would continue to occur after its generation. Figure 3(b) showed the variability of the current under different rotation speeds at $1.0 \mathrm{~A}$. At $4 \mathrm{r} / \mathrm{min}$ and $240 \mathrm{r} / \mathrm{min}$, the variability of current was $0.02 \%$ and $0.12 \%$. At higher speed, the variability could increase dramatically after the pulse formation. Severe current fluctuation means that the rolling contact pairs lost the conductive function. Therefore, the pulse of the real-time (a)

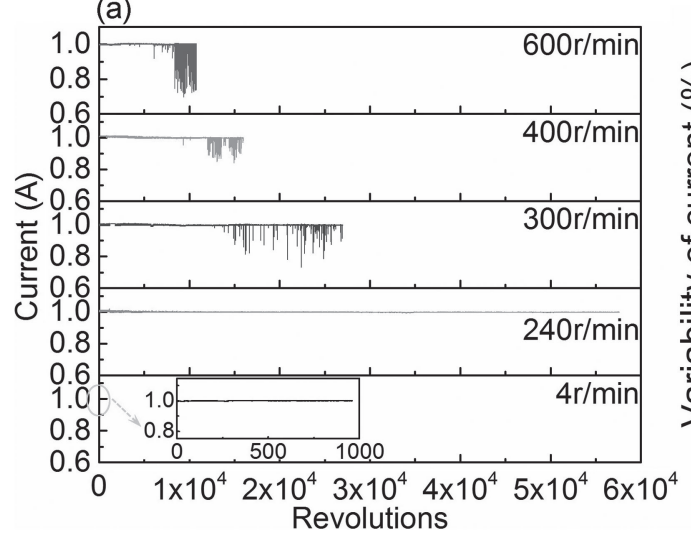

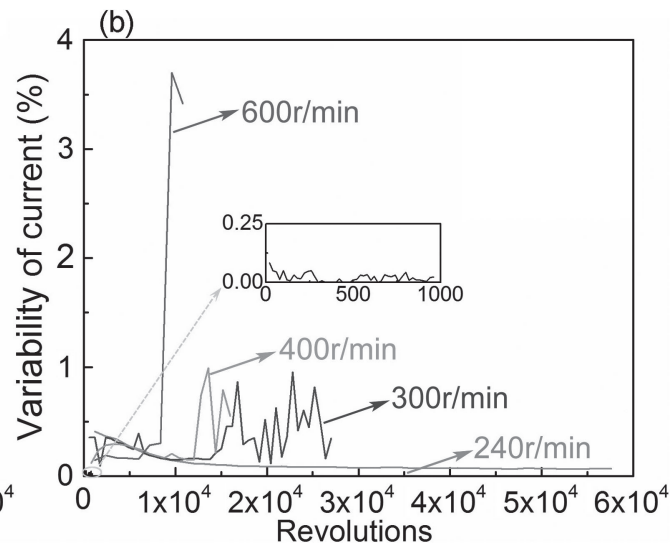

Revolutions

Fig. 3 Conductive properties of $\mathrm{Cu} / \mathrm{Cu}$ rolling pairs at different rotation speeds. (a) The real-time current; (b) The variability of the current. 

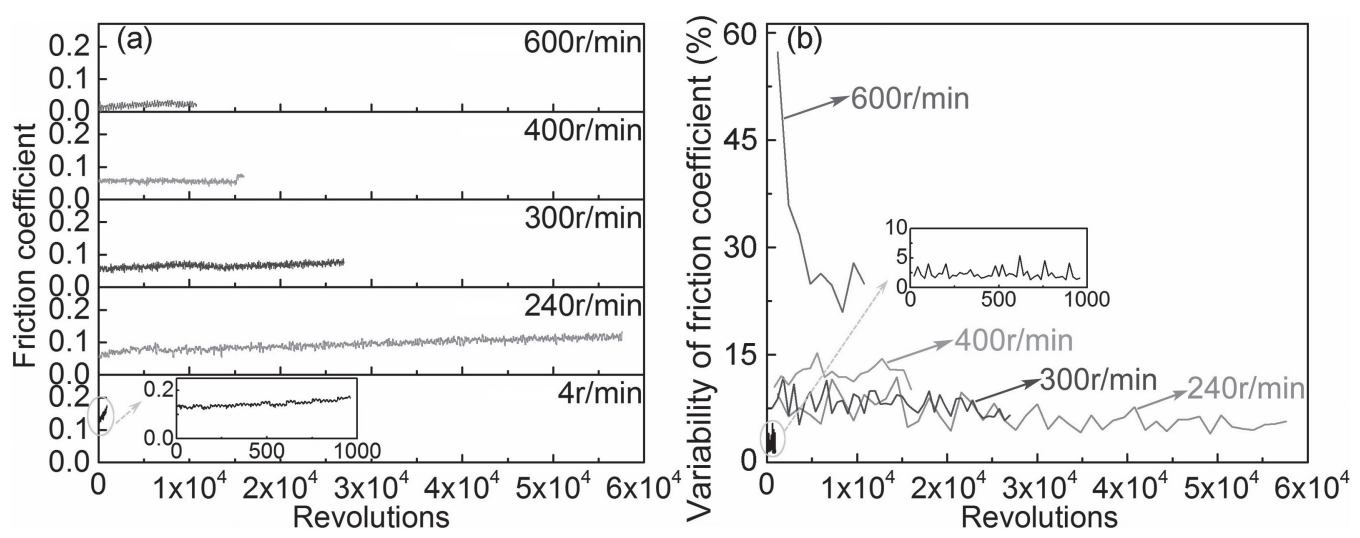

Fig. 4 Tribological properties of $\mathrm{Cu} / \mathrm{Cu}$ rolling pairs at different rotation speeds. (a) The real-time friction coefficient; (b) The variability of the friction coefficient.
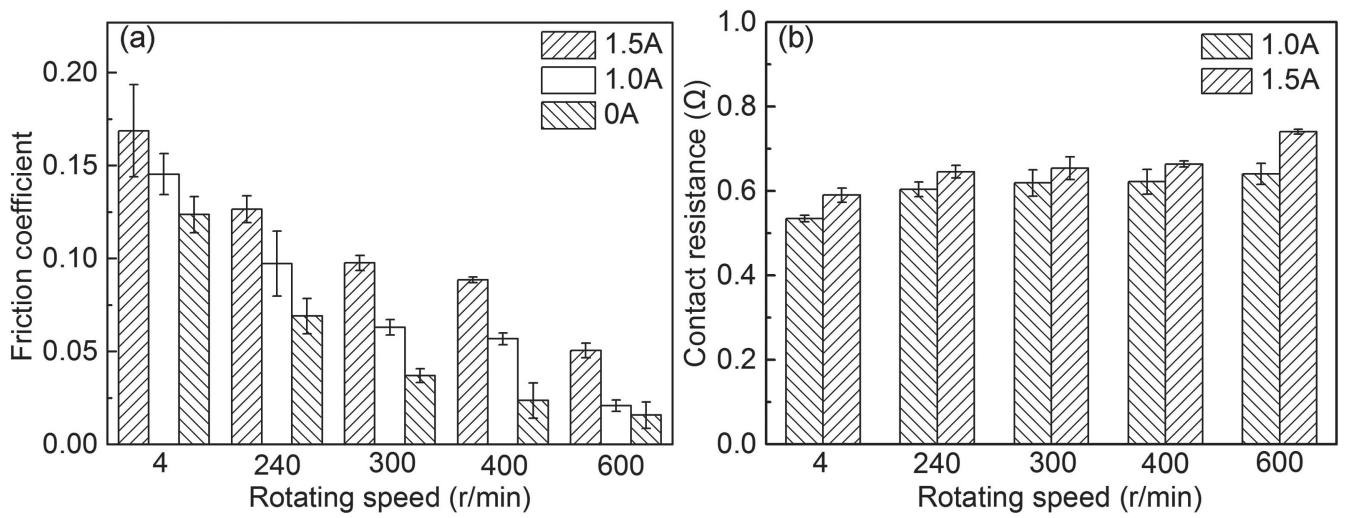

Fig. 5 Rotation speed response of friction coefficient and conductivity with different rotation speeds under different current conditions.

(a) Average friction coefficient; (b) Average contact resistances.

current could be considered as lifetime criterion of the discdisc rolling current-carrying pairs. It was obviously that the lifetime decreased with the rotation speed.

\subsection{Tribological properties of $\mathrm{Cu} / \mathrm{Cu}$ rolling at different rotation speeds}

At the same time, the synchronous friction coefficient was shown in Fig. 4(a). It was found that the real-time friction coefficient increased very slowly. At various rotation speed from $4 \mathrm{r} / \mathrm{min}$ to $600 \mathrm{r} / \mathrm{min}$, the average values of the friction coefficient were $0.145,0.097,0.063,0.057$, and 0.021 , respectively. The variability of friction coefficient under different rotation speeds at $1.0 \mathrm{~A}$ was shown in Fig. 4(b). Accompanied by the current pulse in Fig. 3(a), the friction coefficient of the rolling electric contact did not show the concomitant violent fluctuation. Even after rolling for $4 \mathrm{~h}$ at $240 \mathrm{r} / \mathrm{min}$, the variability of the friction coefficient was not increased. These results revealed that the friction coefficient was relatively stable and cannot be considered as lifetime criterion of the disc-disc rolling current-carrying pairs.

\subsection{The speed dependency of tribological and con- ductive behaviors}

To further analyse the speed dependency of tribological and conductive behaviors, the average friction coefficient and the average contact resistance were summarized in Fig. 5. In Fig. 5(a), whether the current was applied or not, the friction coefficient always went down with the rotation speed going up. For example at $1.5 \mathrm{~A}$, the average values of the friction coefficient were $0.169,0.127,0.098,0.088$ and 0.050 when the rotation speed increased from $4 \mathrm{r} / \mathrm{min}$ to $600 \mathrm{r} / \mathrm{min}$. Many researchers have reported the similar results that the friction coefficient could decrease with the increasing of speed..$^{5,21-23)}$ As the rotation speed increased, the contact time between the asperities of the friction pairs became shorter, and the surface of the friction pairs did not have enough time for adhesion and thus the friction coefficient became smaller. ${ }^{5)}$ The average contact resistance under different rotation speeds was summarized in Fig. 5(b). The contact resistances increased from $0.535 \Omega$ to $0.641 \Omega$ at $1.0 \mathrm{~A}$ and increased from $0.590 \Omega$ to $0.740 \Omega$ at $1.5 \mathrm{~A}$. Therefore, higher rolling speeds can not only have an important influence in the tribological properties but also diminish conductive properties.

Another obvious result was that the current-carrying friction coefficient was always higher than the mechanical one at the same rotation speed, and it increased with the applied current. The higher friction coefficient of currentcarrying friction pairs may be related to the adhesion caused by additional Joule heat. ${ }^{4,12,24)}$ Meanwhile, the contact resistance at $1.5 \mathrm{~A}$ was always higher than that at $1.0 \mathrm{~A}$ under the same rotation speed. The deterioration of contact resistance on the current-carrying surface was probably related to the surface oxidation. ${ }^{13,25}$ ) 


\subsection{The failure life of rolling current-carrying $\mathrm{Cu}$ pairs}

In general, the failure life refers to the time from safe and stable use to failure of friction pairs. Current-carrying friction pairs undertake double functions of current transmission and wear-resisting. In previous work of sliding current-carrying contact, the friction coefficient and the conductivity often worsen concurrently and had a strong coupling relationship. ${ }^{26,27)}$ However, in present results, the real-time current showed obvious pulse fluctuation while the friction coefficient still remained stable (Fig. 3 and Fig. 4). The real-time current fluctuation would affect the current carrying efficiency and stability of the friction pair and the conductivity of the material decreased. ${ }^{20)}$ Therefore, the sharp fluctuation of the real-time current was taken as the failure criterion for rolling current-carrying pairs.

Figure 6 showed the life span of the rolling currentcarrying pairs with different rotation speeds and currents. For example at $1.0 \mathrm{~A}$, the failure life of the friction surface were 13500,12000 and 8400 revolutions when the rotation speed was 300,400 and $600 \mathrm{r} / \mathrm{min}$. When the current increased to $1.5 \mathrm{~A}$, the failure life decreased to 4500,4000 and 3600 revolutions. Moreover, the corresponding life further declined to 3000,2000 and 1200 revolutions when the current was set as 2.0 A. Therefore, both the speed and the current accelerated the failure process of the rolling currentcarrying pairs.

\subsection{Characterization of the rolling surfaces}

The tribological and conductive behaviors of rolling $\mathrm{Cu}$ pairs are depended on the states of the contact area, which are affected by the co-effects of rotation speed and current.

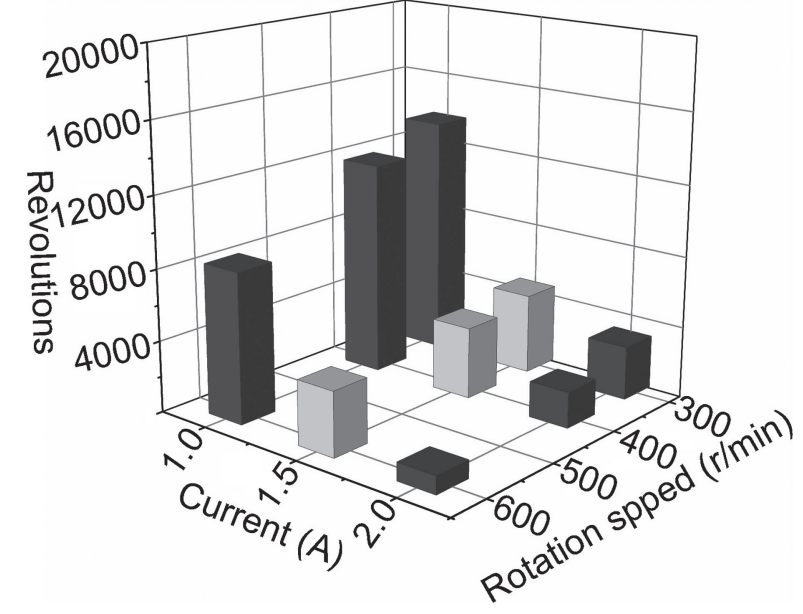

Fig. 6 The life span of the rolling current-carrying pairs with different rotation speeds and currents.

To understand the speed dependency of tribological and conductive behaviors mentioned above, the morphologies of wear surface were observed by OM, SEM and the components were analyzed by EDS.

Figure 7 showed the characterization results of the rolling samples prepared at different rotation speeds with a constant current 1A. As shown in Fig. 7(a), some grinding traces still remained on the original surface, $\mathrm{O}: \mathrm{Cu}$ atomic ratio of Area 1 was only 0.037 , and the surface roughness was $0.24 \mu \mathrm{m}$. When the rotation speed was $4 \mathrm{r} / \mathrm{min}$ (Fig. 7(b)), slight pressing marks were observed by $\mathrm{OM}$ and SEM, O:Cu atomic ratio of Area 2 was 0.050 , and the surface roughness

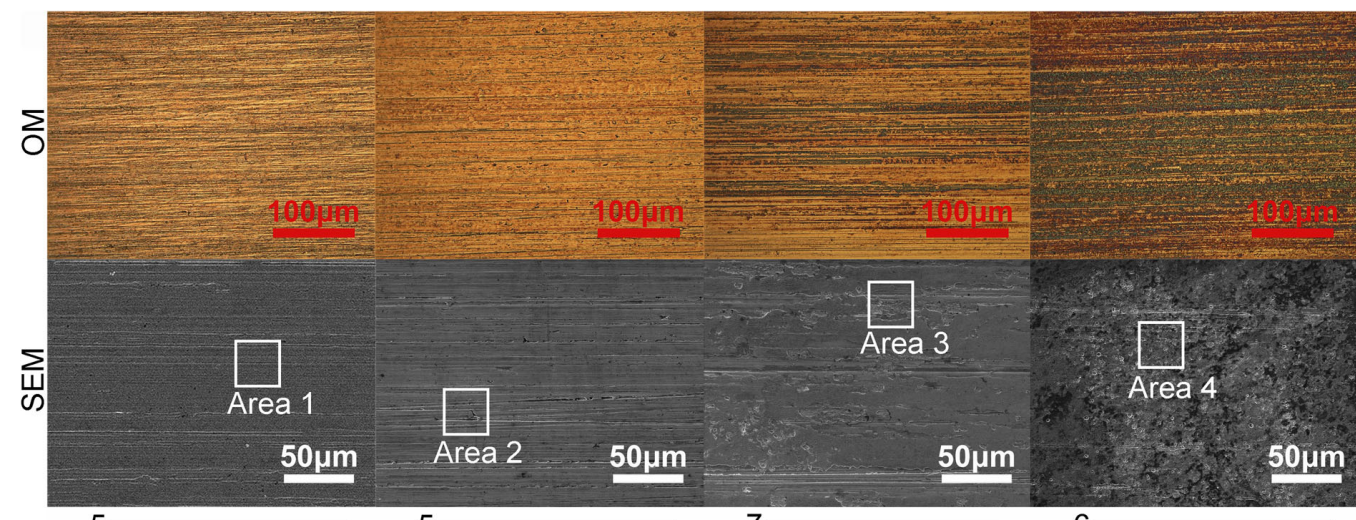

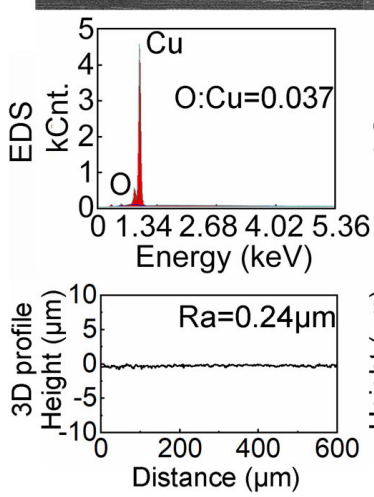

(a) Blank

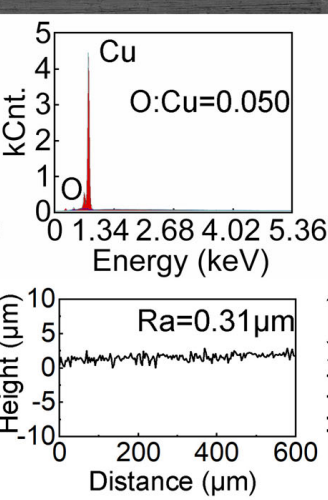

(b) $4 \mathrm{r} / \mathrm{min}-1 \mathrm{~A}$

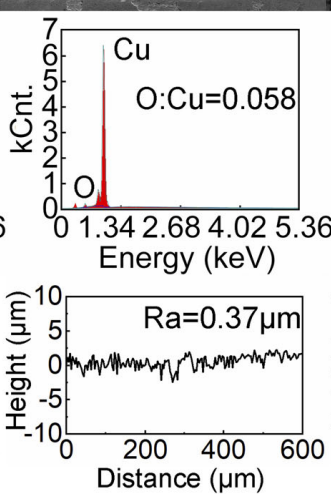

(c) $300 \mathrm{r} / \mathrm{min}-1 \mathrm{~A}$

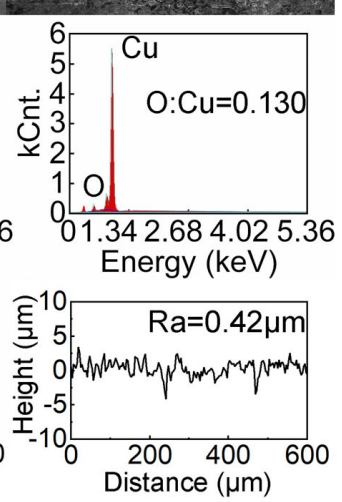

(d) $600 \mathrm{r} / \mathrm{min}-1 \mathrm{~A}$

Fig. 7 OM images (top), SEM and EDS images (middle), 3D profile (bottom) of wear surfaces prepared with different rotation speeds at 1.0 A. (a) Blank sample; (b) $4 \mathrm{r} / \mathrm{min}$; (c) $300 \mathrm{r} / \mathrm{min}$; (d) $600 \mathrm{r} / \mathrm{min}$. 
increased to $0.31 \mu \mathrm{m}$. When the rotation speed increased to $300 \mathrm{r} / \mathrm{min}$ (Fig. 7(c)), the copper sample lost its metallic luster. Some pits were found by SEM, O:Cu atomic ratio of Area 3 reached to 0.058 , the surface roughness was $0.37 \mu \mathrm{m}$. When the rotation speed was $600 \mathrm{r} / \mathrm{min}$ (Fig. 7(d)), the copper sample turned to be dark in the $\mathrm{OM}$ view. There were a large number of the pits on the wear surface, $\mathrm{O}: \mathrm{Cu}$ atomic ratio of Area 4 increased to 0.130 and the surface roughness reached to $0.42 \mu \mathrm{m}$. Based on the results in Fig. 3, it was noted that the formation of pits was always accompanied by the current pulse.

Another series of samples were prepared at the same rotation speed $600 \mathrm{r} / \mathrm{min}$ with different currents. On the mechanical rolling surface (Fig. 8(a)), grinding traces were flatten by rolling and the $\mathrm{O}: \mathrm{Cu}$ atomic ratio of Area 5 was 0.102 . When $0.5 \mathrm{~A}$ current was applied on the rolling pairs, pits were formed and the $\mathrm{O}: \mathrm{Cu}$ atomic ratio of Area 6 increased to 0.113 (Fig. 8(b)). When the current increased to $1.5 \mathrm{~A}$ and $2.0 \mathrm{~A}$, the white pitting phenomenon became more obvious and the $\mathrm{O}: \mathrm{Cu}$ atomic ratio increased to 0.150 (Fig. 8(c) and Fig. 8(d)). The surface roughness was $0.33 \mu \mathrm{m}, 0.37 \mu \mathrm{m}, 0.48 \mu \mathrm{m}, 0.55 \mu \mathrm{m}$, respectively. Therefore, the current could also promote the formation of pits and the surface oxidation. ${ }^{14,19,28)}$

Erosion pits and current pulse were the typical characteristics of the arc between the current-carrying contact pairs. ${ }^{29-31)}$ Based on the surface characterization and the current-carrying behaviors, it was speculated that arc discharge should take place under some conditions of high speed and large current. In Fig. 4(b), higher variability of the friction coefficient indicated the copper-copper contact lost its stabilization at higher speed. An unstable contact could provide the gaps for the arc discharging. ${ }^{20)}$ Meanwhile, the faster rotation speed could induce a higher frictional temperature, which was beneficial to the excitation of electrons. The effect of rotation speed on the average temperature was summarized in Fig. 9(a). Before the rolling experiment, the surface temperature of friction pair was $14^{\circ} \mathrm{C}$ and the temperature rise was more obvious at higher speed. Larger current could also promote arc generation because of the higher potential difference and more Joule heating. ${ }^{12)}$ Figure 9(b) showed average temperature rise caused by additional Joule heat on the current-carrying surface. Therefore, the arc formatted more easily at high speed and large current. The instantaneous discharge of arc could cause the current to fluctuate violently (Fig. 3(a)). Frictional heating, Joule heating and arc discharge were favorable for oxidation reaction of copper. ${ }^{32}$ ) In addition, the current would induce electrochemical oxidation on $\mathrm{Cu}$ surface, which could further aggravate the surface oxidation. ${ }^{19,33)}$ The $\mathrm{O}: \mathrm{Cu}$ atomic ratio on worn surface based on EDS was shown in Fig. 10. It was found that the oxidation degree increased with the increasing of rotation speed (Fig. 10(a)) and current (Fig. 10(b)).

After the oxidation, the metal-oxides-metal contact was formed in the contact area (Fig. 10(c)). ${ }^{34-36)}$ The effect of surface oxidation on the conductivity of the wear surface could be illustrated by conductive AFM scanning. The topography (upper), surface current distribution (middle) and volt-ampere curves (lower) were shown in Fig. 11. From Fig. 11(a) to Fig. 11(d), the O:Cu atomic ratio increased from 0.037 to 0.130 . On the blank sample surface (Fig. 11(a)), the

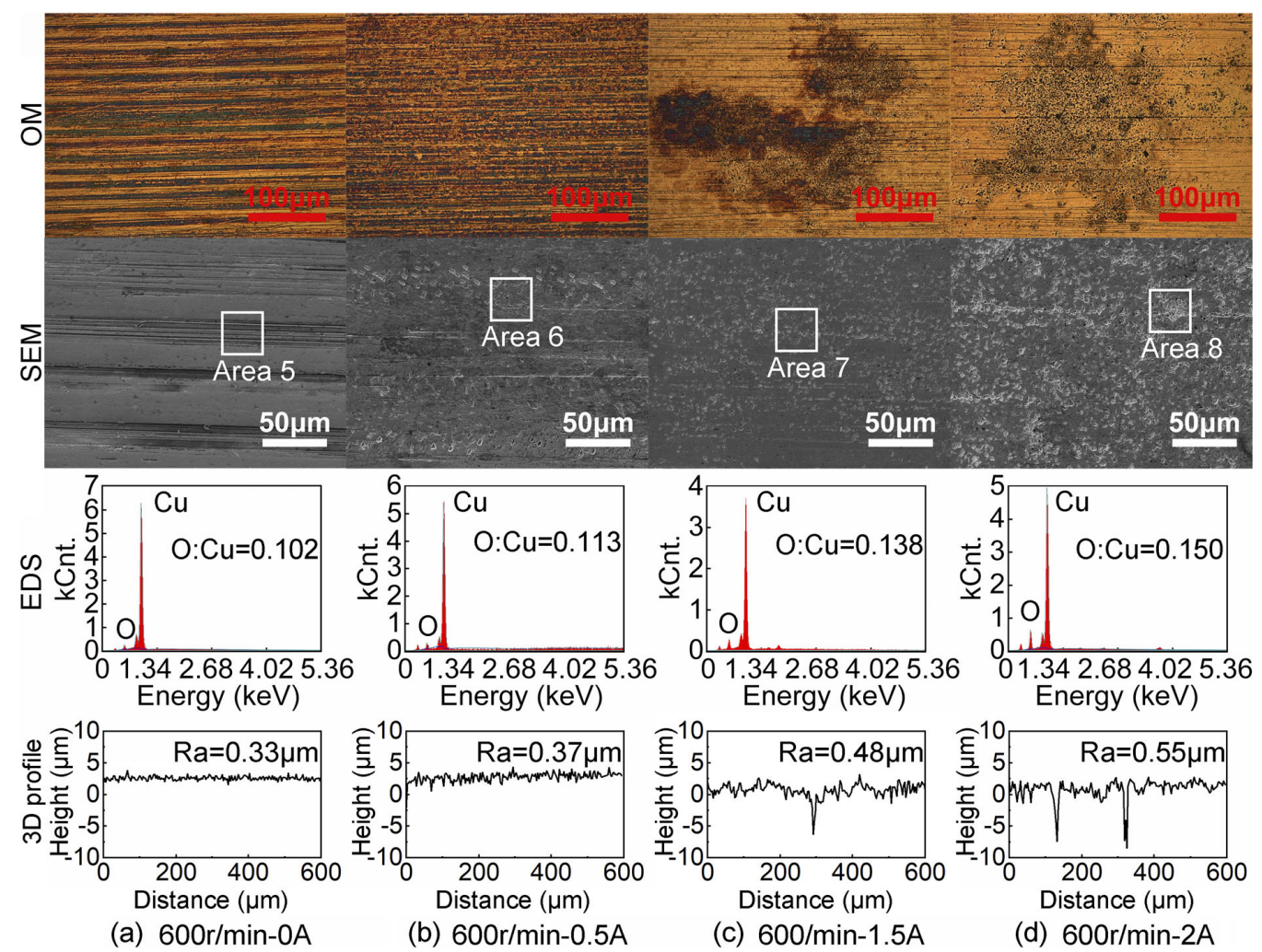

Fig. 8 OM images (top), SEM and EDS images (middle), 3D profile (bottom) of wear surfaces with different currents at $600 \mathrm{r} / \mathrm{min}$.

(a) $0 \mathrm{~A}$; (b) $0.5 \mathrm{~A}$; (c) $1.5 \mathrm{~A}$; (d) $2.0 \mathrm{~A}$. 

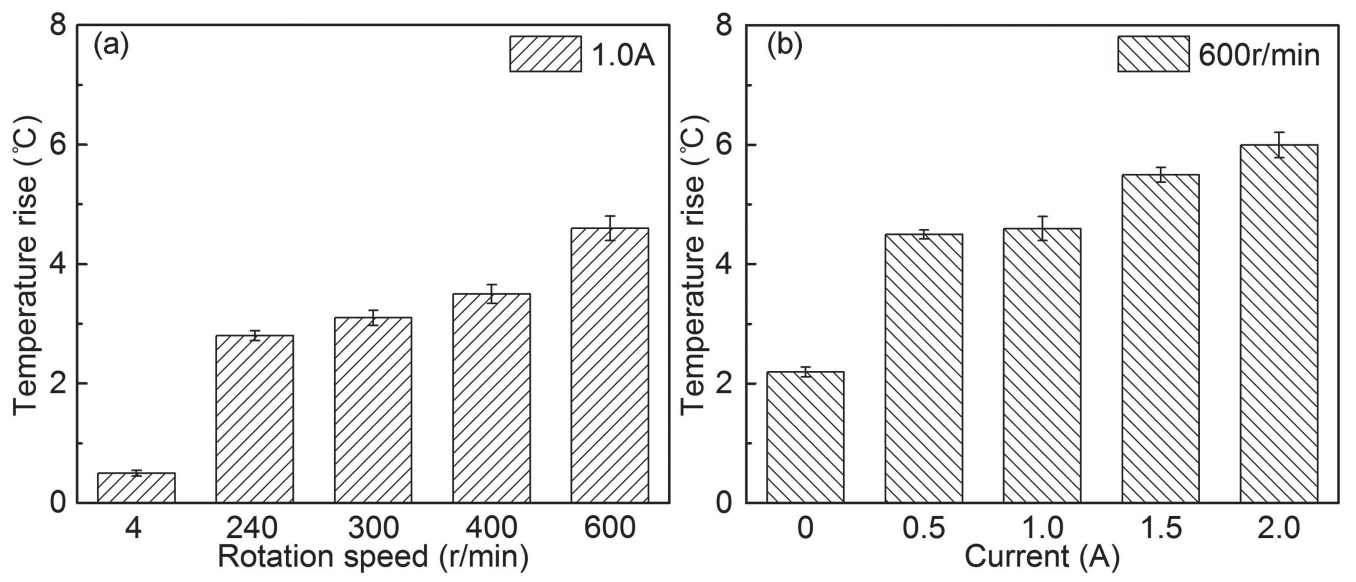

Fig. 9 Temperature rise of the surface after rolling at different rotation speed (a) and current (b).
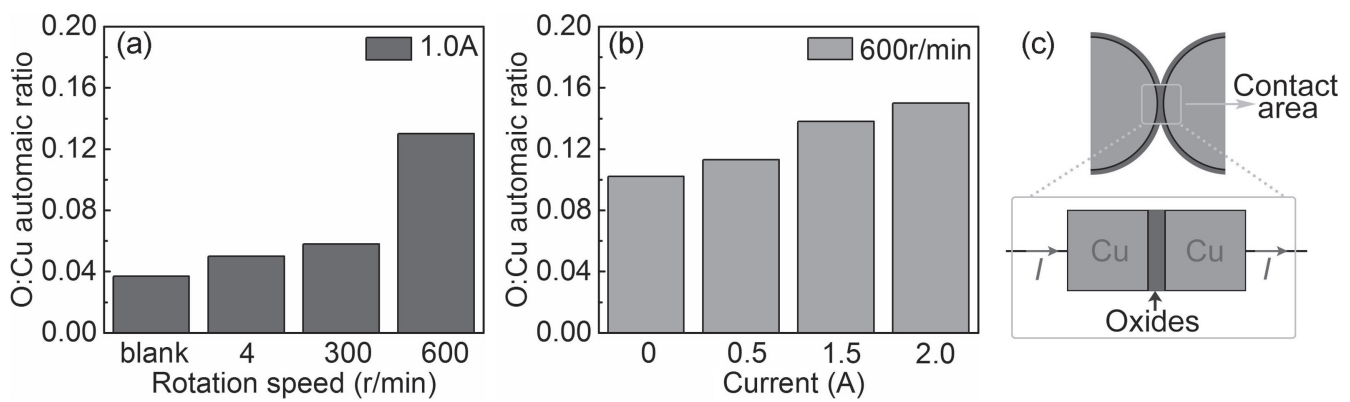

Fig. 10 Oxidation degree at different rotation speeds and currents. (a) Speed effect; (b) Current of effect; (c) Diagram of the surface oxides.
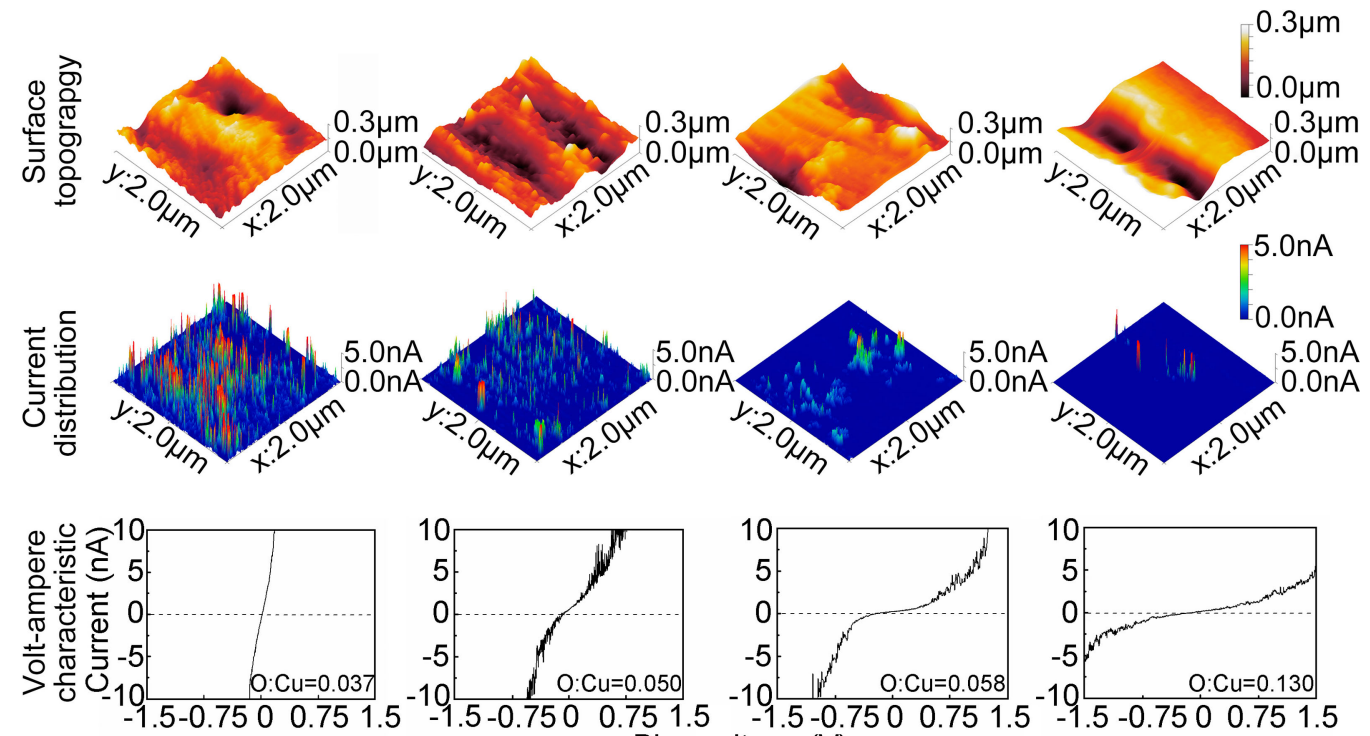

(a) Blank

(b) $4 \mathrm{r} / \mathrm{min}-1 \mathrm{~A}$

(c) $300 \mathrm{r} / \mathrm{min}-1 \mathrm{~A}$

(d) $600 \mathrm{r} / \mathrm{min}-1 \mathrm{~A}$

Fig. 11 Topography (upper), surface current distribution (middle) and volt-ampere curves (lower) observed by AFM on different samples rolled at 1.0 A. (a) Blank sample; (b) $4 \mathrm{r} / \mathrm{min}$; (c) $300 \mathrm{r} / \mathrm{min}$; (d) $600 \mathrm{r} / \mathrm{min}$.

current in most of the scan area could attain $5 \mathrm{nA}$ (middle). The sub-linear volt-ampere curve (lower) indicated there was an approximate ohmic contact on the original surface. When the rotation speed was $4 \mathrm{r} / \mathrm{min}$ (Fig. 11(b)), the slight friction marks appeared (top) and the surface current clearly decreased (middle). From volt-ampere curves (lower), the current increased a little slowly with the voltage and it reached about $10 \mathrm{nA}$ at $0.75 \mathrm{~V}$. When the rotation speed was $300 \mathrm{r} / \mathrm{min}$ (Fig. 11(c)), the surface current dropped significantly (middle). The current increased very slowly with the voltage and it reached about $2.5 \mathrm{nA}$ at $0.75 \mathrm{~V}$. On the worn surface rolled at $600 \mathrm{r} / \mathrm{min}$ (Fig. 11(d)), the conductive area 
dropped dramatically (middle) and it reached about $0.75 \mathrm{nA}$ at $0.75 \mathrm{~V}$ (lower). The decline of surface conductivity and the descending slopes of volt-ampere curves further confirmed the weakening effect of oxidation on the conductivity. These results conformed to those in Figs. 5(b) and 10(a).

In summary, the speed dependency of tribological and conductive behaviors of the rolling current-carrying pairs was investigated. Similarly to the traditional sliding electric contact, the arc discharge was also the decisive factor of conduction failure and material damage. However, the rolling electric contact did not represent a close relevance of the tribological failure and conductive failure (Fig. 3 and Fig. 4). Probably because the contact area $\left(0.25 \mathrm{~mm}^{2}\right)$ was too small to keep a steady electric contact after the deterioration of surface quality during rolling. The mass loss was not detected after the test, but the current pulse induced by arc still indicated that the friction pair had failed. The data in Fig. 6 revealed that both the rotation speed and applied current were the effective acceleration factor for lifetime test. The results in this paper may provide some fundamental supporting for the design and operation of the rolling current-carrying rotational joints.

\section{Conclusion}

Effect of rotation speed on the tribological and conductive behaviors of rolling current-carrying pairs was studied. The friction coefficient, real-time current and their variability were monitored. The mechanism of surface damage was discussed based on the observation of OM, SEM and EDS. The weakening effect of oxidation on the conductivity was detected by AFM in current mode. A life criterion of the rolling current-carrying pairs was proposed based on the arc-induced current pulse. The conclusions are summarized as follows:

(1) Whether the current was applied or not, the friction coefficient decreased with the increasing of rotation speed. At the same speed, the current-carrying friction coefficient was always higher than the purely mechanical one and it increased with the increasing of current.

(2) The erosion pits and the current pulse indicated the formation of arc under high speed and large current conditions. After that, the mechanism of surface damage transformed from mechanical deformation to arc erosion. The arc discharge could be proposed as a life criterion of the rolling current-carrying pairs because of the instability of conductive function.

(3) With the increasing of rotation speed and current, the surface oxidation became more serious. Conductive AFM scanning demonstrated that surface conductivity could be weakened by such serious oxidation.

\section{Acknowledgments}

This work was supported by National Natural Science Foundation of China (51775173, U1804252) and State Key Laboratory of Electrical Insulation and Power Equipment (EIPE19212).

\section{REFERENCES}

1) T. Miyake: Mater. Trans. 56 (2015) 872-877

2) G.X. Chen, H.J. Yang, W.H. Zhang, Y.T. Lu, S.D. Zhang and Z.R. Zhou: Proc. Inst. Mech. Eng., Part J 227 (2013) 1406-1417.

3) W.F. Wei, W. Jie, G.Q. Gao, G. Zhen and G.N. Wu: IEEE Trans. Plasma Sci. 44 (2016) 2438-2445.

4) S.Y. Huang, Y. Feng, H.J. Liu, K.W. Ding and G. Qian: Mater. Sci. Eng. A 560 (2013) 685-692.

5) Z.Y. Huang, H.X. Zhai, M.Q. Li, X.H. Liu and Y. Zhou: Tribol. Trans. 57 (2014) 300-307.

6) N. Argibay, J.A. Bares, J.H. Keith, G.R. Bourne and W.G. Sawyer: Wear 268 (2010) 1230-1236.

7) H.J. Zhang, L.M. Sun, Y.Z. Zhang and B. Shangguan: Tribol. Trans. 57 (2014) 1157-1163.

8) J.X. Chen, F. Yang, K.Y. Luo, M.L. Zhu, Y. Wu and M.Z. Rong: Rev. Sci. Instrum. 86 (2015) 125110.

9) Z.S. Xu, X.L. Shi, Q.X. Zhang, W.Z. Zhai, X.X. Li, J. Yao, L. Chen, Q. Zhu and Y.C. Xiaov: Tribol. Lett. 55 (2014) 393-404.

10) K. Hirasata, K. Hayashi and Y. Inamoto: Wear 263 (2007) 790-800.

11) P. Jayashree, M. Federici, L. Bresciani, S. Turani, R. Sicigliano and G. Straffelini: Tribol. Lett. 66 (2018) 123.

12) Y.Z. Zhang, Z.H. Yang, K.X. Song, X.J. Pang and B. Shangguan: Friction 1 (2013) 259-270.

13) X.L. Xie, L. Zhang and J.K. Xiao: Trans. Nonferrous Met. Soc. China 25 (2015) 3029-3036.

14) Y.X. Sun, C.F. Song, Z.L. Liu, J.W. Li, Y.M. Sun, S.G. Bao and Y.Z Zhang: Wear 436 (2019) 203023.

15) C. Santoro, R. Hayes and J. Herman: Brushless slip ring for high power transmission, AIAA SPACE 2009 Conference \& Exposition, (Pasadena, California, 2009).

16) A.M. Aquib, J.P. Srivastava, N.R. Duhan and P.K. Sarkar: IOP Conf. Ser.: Mater. Sci. Eng. 377 (2018) 012098.

17) K.L. Johnson: Contact Mechanics, (Cambridge University Press, London New York New Rochelle, 1987).

18) K.J. Ono, T. Mifune and M. Meshii: Philos. Mag. 17 (1968) 235-240.

19) Y.X. Sun, C.F. Song, Z.L. Liu, J.W. Li, L. Wang, C. Sun and Y.Z. Zhang: Tribol. Int. 143 (2020) 106055.

20) Y.Z. Zhang, K.X. Song and S.M. Du: Current-carrying Tribology, (Science Press, Beijing, 2016).

21) P. Jayashree, S. Turani and G. Straffelini: Tribol. Int. 140 (2019) 105850 .

22) Q. Wei, W. Gao, Q. Yang and X. Li: J. Non-Cryst. Solids 514 (2019) 90-97.

23) H.X. Zhai and Z.Y. Huang: Wear 257 (2004) 414-422.

24) Y. Kubota, S. Nagasaka, T. Miyauchi, C. Yamashita and H. Kakishima: Wear 302 (2013) 1492-1498.

25) P. Wang, H.B. Zhang, J. Yin, X. Xiong and C.Y. Deng: Tribol. Int. 116 (2017) 310-319.

26) Z.H. Yang, Y.X. Ge, Z. Xu, S.G. Bao, Y.Z. Zhang and J.W. Zhang: Materials 12 (2019) 2881.

27) H.C. Chen, Z.Q. Cao, G.Y. Chen, B. Wang, C.Y. Gong, Z.X. Zhang and Z.B. Cai: Rev. Sci. Instrum. 90 (2019) 095103.

28) C.F. Song, Z.L. Liu, X.B. Hou, L. Wang and Y.Z. Zhang: Proc. Inst. Mech. Eng., Part J 233 (2019) 1407-1414.

29) Y.Y. Zhang, Y.Z. Zhang, S.M. Du, C.F. Song, Z.H. Yang and B. Shangguan: Tribol. Int. 123 (2018) 256-265.

30) H.J. Yang, Y. Hu, G.X. Chen, W.H. Zhang and G.N. Wu: Tribol. Trans. 57 (2014) 86-93.

31) M. Iwasaki, K. Shimada, K. Kudo, Y. Tamagawa and H. Horikawa: Mater. Trans. 52 (2011) 1410-1417.

32) W.F. Wei, Y.J. Song, Z.F. Yang, Q. Guo, X. Pan, M. Lu, C.J. Tu, M.L. Chen and G.N. Wu: Materials 12 (2019) 435.

33) Q.D. Xiao and S. Wu: Adv. Appl. Ceram. 113 (2014) 381-388.

34) M. Bartošík, D. Škoda, O. Tomanec, R. Kalousek, P. Jánsky, J. Zlámal, J. Spousta and P. Dub: Phys. Rev. B 79 (2009) 195406.

35) P.J. Ding, W.A. Lanford, S. Hymes and S.P. Murarka: Appl. Phys. Lett. 64 (1994) 2897-2899.

36) Z.L. Liu, C.F. Song, J.W. Li, X.B. Hou, L. Wang and Y.Z. Zhang: Mater. Trans. 61 (2020) 111-118. 